\title{
Bacterial aetiology of chronic otitis media with effusion in children - risk factors
}

\author{
Izabela Korona-Glowniak ${ }^{1 *} \mathbb{D}$, Agata Wisniewska², Marek Juda ${ }^{1}$, Karolina Kielbik' , Grazyna Niedzielska ${ }^{2}$ and \\ Anna Malm ${ }^{1}$
}

\begin{abstract}
Background: Otitis media with effusion (OME) may occur spontaneously because of poor Eustachian tube function or as an inflammatory response following AOM. Bacterial involvement in OME has been widely reported, with various available methods to identify pathogens from middle ear effusion, including traditional culture methods and polymerase chain reaction (PCR).

Objectives: The primary goal of this study was to evaluate the bacteriological profile of middle ear effusion in OME. Risk factors of the bacterial OME aetiology were also identified.

Methods: Middle ear effusions (MEF) from 50 children, aged 2-8 years, diagnosed by ENT and undergoing routine tympanostomy tube placement were collected. MEF samples were streaked on standard microbiological media. Next, DNA was isolated from MEF samples and analysed with multiplex PCR for Streptococcus pneumoniae, Haemophilus influenzae, Moraxella catarrhalis and Alloiococcus otitidis.

Results: In multiplex PCR assay 37 (74\%) of 50 children were positive for at least one of the four microorganisms. In 27.0\% positive children multiple bacterial pathogens were identified. A. otitidis was the most frequently identified in positive MEF children (59.5\%). By multiplex PCR, H. influenzae, S. pneumoniae and M. catarrhalis were detected in 24, 18 and $8 \%$ of OME patients, respectively. There was significant association between bilateral infection and $H$. influenzae aetiology of OME.

Conclusions: Overall we found OME predominantly a single otopathogen infection caused mainly by A. otitidis, which is difficult in identification using standard culture method, ahead to S. pneumoniae and H. influenzae. However, one third of MEF samples had multiple bacterial pathogens.
\end{abstract}

Keywords: Otitis media with effusion, Otopathogens, Risk factors

\section{Introduction}

Otitis media with effusion (OME) is one of the most common otologic diseases of childhood. OME may occur spontaneously, however it can be persistent in some cases, as a result of poor Eustachian tube function or as an inflammatory response following acute otitis media (AOM) [1, 2]. About $80 \%$ of the children suffered

\footnotetext{
*Correspondence: iza.glowniak@umlub.pl

'Department of Pharmaceutical Microbiology, Medical University of Lublin, 1 W. Chodzki Str, 20-093 Lublin, Poland

Full list of author information is available at the end of the article
}

from this disease by the age of 10 with the highest prevalence at ages of 2 and 5. OME exhibits nonpurulent middle ear effusion with the absence of acute infection typical for AOM appearing as middle ear inflammation, including fever and otalgia [1, 2]. It has been postulated that the Eustachian tube short length, horizontal position, and reduced rigidity in the pediatric population may permit the reflux of naso- and oropharyngeal microbes into the middle ear cavity, explaining the higher incidence of OME in children compared to adults [1]. 
Bacterial involvement in OME has been widely reported, with various available methods to identify pathogens from middle ear effusion, including traditional culture methods and polymerase chain reaction (PCR). Traditional culturebased techniques have isolated Streptococcus pneumoniae, Haemophilus influenzae, Moraxella catarrhalis and Staphylococcus epidermidis as the most common pathogens in OME [2]. However, in chronic OME (duration <3 months), middle ear fluid (MEF) cultures yield positive results for only $20-30 \%$ of patients [2]. Polymerase chain reaction (PCR) and 16S rRNA sequencing-based methods identified different species as a possible pathogens in the development of OME. One such emerging potential pathogen is Alloiococcus otitidis, which has been isolated from middle ear aspirates with increasing frequency in the last decade [3-5]. Therefore, the primary goal of this study was to evaluate the bacteriological profile of middle ear effusion in OME with use of traditional culture method and PCR technique. This is the first study identifying the risk factors of the infection by particular otopathogens in OME.

\section{Materials and methods \\ Patients}

This prospective study enrolled 50 children, aged between 2 and 8 years who were diagnosed with OME during 2017-2018. All children with preliminary OME diagnosis by paediatricians as well as children directly diagnosed by Ear-Nose-and-Throat (ENT) specialists, were assessed for eligibility. Eligible children, once the OME diagnosis was confirmed by the ENT specialists in the Department of Pediatric Otolaryngology, Phoniatrics and Audiology, Medical University of Lublin, Poland, were enrolled to the study. The criteria for surgery were the presence of middle ear effusion for more than 3 months and not receiving antibiotic therapy for at least 2 weeks prior to the procedure. Children with tympanic membrane perforations, immunological defects, any malformations, respiratory tract infection and purulent middle ear fluid were excluded.

A total of 68 specimens of middle ear effusions (MEF) were obtained from 50 children (17 females and 33 males, from 2 to 8 years, median age of 4 years). In 19 out of 50 children with bilateral OME, two separate specimens were taken from each ear at the same episode. The rest of the children were diagnosed with unilateral OME. The pathogens which were detected from both ears were double counted. However, for statistical analysis of risk factors associated with OME pathogens were accounted once in a single patient if detected at least in one ear.

Diagnosis of OME was based on video-otoscopy (yellow or amber color, decreased mobility, air fluid level and retracted tympanic membrane), type $\mathrm{B}$ or $\mathrm{C}$ tympanometric curves and absence of otoacoustic emissions.
Children between 5 and 8 years old also underwent pure tone audiometry to evaluate the level of hearing loss. An original questionnaire was developed based on the stateof-the-art literature. The questionnaire included: demographic data (age, sex, residency, social status in personal evaluation), parental smoking, type of delivery, breastfeeding and health status: all types of allergies, number of upper respiratory tract infections per year (more than 6 per year was reported as frequent), duration of the otitis media symptoms, snoring and history of pneumococcal vaccination.

\section{Study procedures}

All of the specimens were obtained during myringotomy, performed as the treatment for OME. Antisepsis of the ear canal before the procedure was performed by installing Octenisept (Schülke\&Mayr) for $1 \mathrm{~min}$. After removing it by suction, myringotomy was carried out, during which dense, mucopurulent discharge draining under pressure from middle ear was found uni- or bilaterally. MEF sample was collected from the ear with the use of sterile suction needle inserted into the middle ear cavity through the incision in the tympanic membrane. The samples were placed in sterile eppendorf tubes and, maintained in $37^{\circ} \mathrm{C}$, transported immediately to the laboratory. The remaining amount of exudate had been aspirated. Next, in 29 (46.8\%) patients ventilation drainage of the middle ear had been placed.

\section{Laboratory procedures}

MEF samples were inoculated on Mueller-Hinton agar with 5\% sheep blood, Mueller-Hinton agar with 5\% sheep blood with $0.5 \mathrm{mg} / \mathrm{L}$ of gentamicin for selective cultivation of pneumococci, Haemophilus chocolate agar (BioMerieux) for selective cultivation of Haemophilus sp. and Chapman agar for selective cultivation of staphylococci. Plates were incubated for $24-48 \mathrm{~h}$ at $35^{\circ} \mathrm{C}$ under aerobic conditions or in $5 \% \mathrm{CO}_{2}$ enriched atmosphere. Pneumococci were identified by colony morphology, susceptibility to optochin ( $5 \mu \mathrm{g}$, BioMereieux), and bile solubility; identification was confirmed by a slide agglutination test (Slidex Pneumo-Kit, BioMerieux). S. pyogenes was identified by colony morphology, susceptibility to bacitracin (Bacitracin disk, 0.04 U, Sigma-Aldrich) and confirmed by slide agglutination test Slidex Strepto plus (BioMerieux). M. catarrhalis and $H$. influenzae were identified by macroscopic, microscopic and biochemical assays by API NH microtest (BioMerieux). Isolates of $S$. aureus were identified by colony morphology, biochemical activities (ID32 STAPH, BioMerieux), coagulase test and a slide agglutination test (Slidex StaphKit, BioMerieux).

Next, DNA from MEF samples were extracted using QIAGEN QIAamp DNA Mini Kit (Qiagen, USA) 
according to the manufacturer's instructions and analyzed with multiplex PCR with the use of method described elsewhere [5]. The PCR mixture contained the following primers for A. otitis $(3.6 \mu \mathrm{M}), H$. influenzae $(1.8 \mu \mathrm{M}), M$. catarrhalis $(0.6 \mu \mathrm{M})$ and $S$. pneumoniae $(0.2 \mu \mathrm{M})$ as well as common reverse primer $(0.8 \mu \mathrm{M})$. Moreover the concentration of $\mathrm{MgCl}_{2}$ was $2 \mathrm{mM}, 3$ units of Taq polymerase (Thermo Scientific) were used per reaction. The reaction profile was $3 \mathrm{~min}$ of initial denaturation and 35 cycles of $94^{\circ} \mathrm{C}$ for $30 \mathrm{~s}, 66^{\circ} \mathrm{C}$ for $1.5 \mathrm{~min}$ and $72^{\circ} \mathrm{C}$ for $1 \mathrm{~min}$ followed by a $5 \mathrm{~min}$ final extension at $72{ }^{\circ} \mathrm{C}$. The PCR products were separated in $2 \%$ agarose gen in Tris-borate-EDTA buffer and DNA bands were visualized with SimplySafe dye (Euryx) by UV light illumination.

\section{Statistical analysis}

Data processing and analysis were performed using Tibco Statistica Ver. 13.3 (TibcoSoft. Inc.). The results are expressed as percentage or median with range. Univariate analyses were performed using Chi-square or Fisher exact test, depending on size of samples and of contingency tables for categorical variables and using Mann-Whitney $\mathrm{U}$ test for continuous variables. Odds ratios (OR) and their 95\% confidence intervals (CI) were calculated. Statistical significance was set if the 2-tailed $p$ value was $<0.05$.

\section{Results}

Of the 68 MEF specimens, positive culture was observed in $6(8.8 \%)$ specimens. By PCR, altogether 50 (73.5\%) specimens were positive for one of the four otopathogens. Of these 50 positive samples, 12 (24\%) had 2-3 bacterial species detected. By combination of culture and PCR, 50 (73.5\%) of the 68 OME specimens were positive for bacterial pathogens. Comparing the results of otopathogen isolation by microbiological cultures and PCR tests, the sensitivity and negative predictive values for culture method were very low and amounted to $12.0 \%$ (95\% CI $0.05-0.24)$ and $29.0 \%$ (95\%CI $0.18-0.42)$, respectively (Table S1). As shown in Table 1 by culture

Table 1 Frequency of otopathogens in 68 samples of middle ear effusions from otitis media patients

\begin{tabular}{llll}
\hline Pathogen & \multicolumn{3}{l}{ No. (\%) of positive specimens } \\
\cline { 2 - 4 } & Culture $^{a}$ & PCR & Total \\
\hline A. otitidis & $0(0)$ & $30(44.1)$ & $30(44.1)$ \\
S. pneumoniae & $3(4,4)$ & $9(13,2)$ & $10(14.7)$ \\
H. influenzae & $0(0)$ & $14(20.6)$ & $14(20.6)$ \\
M. catarrhalis & $0(0)$ & $6(8.8)$ & $6(8.8)$ \\
\hline
\end{tabular}

${ }^{a}$ The other pathogens which were detected by culture were Staphylococcus aureus in $2(2.9 \%)$ samples and Coagulase-negative staphylococcus in 1 (1.5\%) sample and PCR, A. otitidis was the most frequent pathogen in OME specimens.

Positive culture results were reported for only $6(10 \%)$ children - S. pneumoniae (3 patients), S. aureus (2 patients) and CNS (1 patient). In multiplex PCR assay, 37 (74\%) of 50 children were positive for at least one of the four microorganisms. In $27.0 \%$ of positive children multiple bacterial pathogens were identified. A. otitidis was the most frequently identified in positive MEF children $(59.5 \%)$ (Table 2). As a single otopathogen, it was observed in 15 positive children (40.5\%). S. pneumoniae was identified in $9(24.3 \%)$ positive children - in $13.5 \%$ as a single otopathogen. $H$. influenzae (33.4\% of positive children) was more frequently identified with the other pathogens (in 7 out of 12 children). Only 4 (10.8\%) of positive MEF children had $M$. catarrhalis identified.

Among 19 patients with bilateral OME the most frequent otopathogen was $H$. influenzae (9/19 patients; 47.4\%). The higher prevalence of this otopathogen in bilateral infection in comparison to unilaterally affected patients was statistically significant (RR 4.9, 95\%CI 1.5$15.8, p=0.005)$. S. pneumoniae was mainly shown as the cause of unilateral OME (8/31 patients; $25.8 \%)$ but without statistical significance (RR 4.9, 95\%CI 0.7-36.2, $p=$ 0.13) (Fig. 1). When analyzing bilateral samples, all patients with $A$. otitidis were infected in both ears $(8 / 8 \mathrm{pa}$ tients). Five out of 9 bilaterally affected patients with $H$. influenzae were infected in both ears and 1 out of 3 patients with $M$. catarrhalis was infected in both ears. $S$. pneumoniae was present in only one bilaterally affected patient, but this otopathogen was detected in only one ear (Table 2).

Demographic and clinical data of studied children were shown in Table 2 together with description of positive children with four tested otopathogens. Statistical analysis indicated $H$. influenzae aetiology as a factor significantly associated with bilateral OME in children. There was a non-statistically significant association $(p<0.1)$ between the presence of bilateral OME and younger age, as well as rural residents (Table 3). Analysis of affecting factors for positive MEF samples in OME patients was determined for S. pneumoniae, H. influenzae, A. otitidis and M. catarrhalis separately. $H$. influenzae as the otopathogen present in MEF specimens was significantly associated with bilateral OME but negatively with breast feeding in OME patients (Table 4). The univariate analysis did not indicate any factors associated with $M$. catarrhalis and $A$. otitidis presence in MEF of OME patients.

\section{Discussion}

In this study, we have determined bacterial aetiology of OME both by bacterial culture isolation and PCR detection of four otopathogens in children undergoing myringotomy. Standard bacterial culture and sensitive molecular detection 
Table 2 Characteristics of children with OME

\begin{tabular}{|c|c|c|c|c|c|}
\hline \multirow[t]{2}{*}{ Characteristics } & \multirow[t]{2}{*}{ Total $(n=50)$} & \multicolumn{4}{|c|}{ MEF positive (\% in group) } \\
\hline & & S. pneumoniae $(n=9)$ & H. influenzae $(n=12)$ & A. otitidis $(n=22)$ & M. catarrhalis $(n=4)$ \\
\hline Age $(y r)^{a}$ & $4(2-8)$ & $5(3-8)$ & $4(2-7)$ & $3.7(3-5)$ & $4(3-6)$ \\
\hline Male sex & $33(66.0)$ & $8(24.2)$ & $6(18.2)$ & $13(39.4)$ & $3(9.1)$ \\
\hline \multicolumn{6}{|l|}{ Social status: } \\
\hline Very good & $26(52.0)$ & $2(7.7)$ & $6(23.1)$ & $11(42.3)$ & $1(3.9)$ \\
\hline Good & $23(46 . .0)$ & $7(30.4)$ & $5(21.7)$ & $10(43.5)$ & $3(13.0)$ \\
\hline Low & $1(2.0)$ & $0(0)$ & $1(100)$ & $1(100)$ & $0(0)$ \\
\hline Rural residence & $19(38.0)$ & $4(21.1)$ & $4(21.1)$ & $10(52.6)$ & $3(15.8)$ \\
\hline Parental smoking & $14(28.0)$ & $4(28.6)$ & $6(42.9)$ & $8(57.1)$ & $2(14.3)$ \\
\hline Breastfeeding & $45(90.0)$ & $9(20.0)$ & $8(17.8)$ & $19(42.2)$ & $4(8.9)$ \\
\hline Cesarean childbirth & $22(44.0)$ & $5(55.6)$ & $4(18.2)$ & $11(50.0)$ & $2(9.1)$ \\
\hline $\begin{array}{l}\text { Bilateral OME: positive samples } \\
\text { from right/left ear }\end{array}$ & 19 (38.0): 15/13 & 1 (5.3): 1/0 & 9 (47.4): 8/6 & 8 (42.1): 8/8 & 3 (15.8): 3/2 \\
\hline Unilateral OME & $31(62.0)$ & $8(25.8)$ & $3(9.7)$ & $14(45.2)$ & $1(3.2)$ \\
\hline Duration of symptoms (days) ${ }^{a}$ & 639 (92-1095) & $548(365-730)$ & $548(183-730)$ & $730(183-1095)$ & $730(365-730)$ \\
\hline Frequent URTI & $39(78.0)$ & $8(20.5)$ & $9(23.1)$ & $15(38.5)$ & $4(10.3)$ \\
\hline Snoring & $34(68.0)$ & $4(11.8)$ & $8(23.5)$ & $16(47.1)$ & $3(8.8)$ \\
\hline Allergy & $7(14.0)$ & $1(14.3)$ & $1(14.3)$ & $1(14.3)$ & $1(14.3)$ \\
\hline Pneumococcal vaccination & $16(32.0)$ & $4(25.0)$ & $5(31.3)$ & $5(31.3)$ & $1(6.3)$ \\
\hline
\end{tabular}

${ }^{a}$ median (range)

techniques have shown that the healthy middle ear is typically a sterile site [6]. Similarly to others, multiplexPCR method had a better performance than conventional culture method in detecting middle ear pathogens in the MEFs samples (74\% versus 10\%, respectively). Low sensitivity $(12 \%)$ of conventional culture methods, their time-consumption, labor-intensiveness and need of experience in microbiological diagnosis convince that multiplex-PCR, being a one-step rapid method, might be considered as a routine diagnostic method in patients with OME $[3,7,8]$. A. otitidis was the most frequent otopathogen $(44 \%)$ in both unilaterally $(42 \%)$ and bilaterally (46.7\%) affected patients, though without statistical significance. This pathogen was not identified in the course of culture method. By multiplex PCR, H. influenzae, S. pneumoniae and $M$. catarrhalis were detected in 24,18 and $8 \%$ of OME patients, respectively, similarly to other reports $[3,8,9]$.

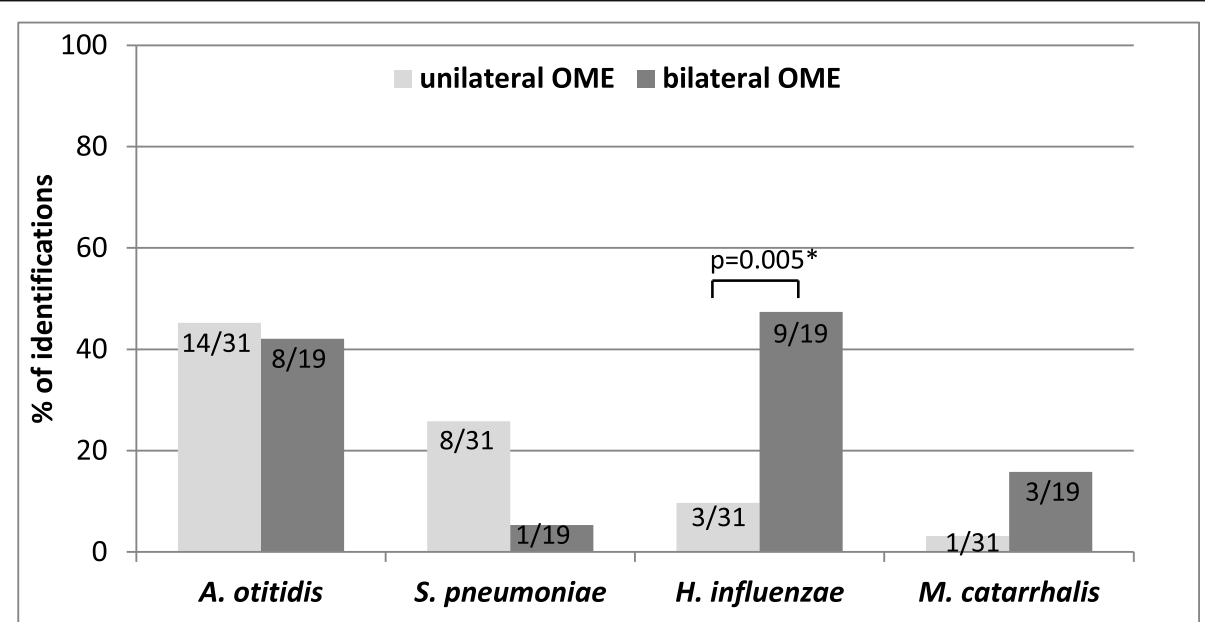

Fig. 1 Prevalence of otopathogens in MEF samples in uni- and bilateral OME with use PCR method. Number of identifications in relation to 31 of unilateral cases and 19 of bilateral cases is presented in each bar 
Table 3 Analysis of risk factors for bilateral OME in children

\begin{tabular}{lll}
\hline Characteristics & OR (95\%Cl) & $p$ value \\
\hline Age (yr) & $0.6(04-1.0)$ & 0.072 \\
Male sex & $1.2(0.4-4.0)$ & 0.78 \\
Good social status & $0.9(0.3-2.7)$ & 0.79 \\
Rural residence & $2.7(0.8-8.9)$ & 0.099 \\
Parental smoking & $0.9(0.2-3.1)$ & 0.84 \\
Breastfeeding & $0.4(0.06-2.4)$ & 0.30 \\
Cesarean childbirth & $0.9(0.3-2.8)$ & 0.83 \\
S. pneumoniae positive & $0.2(0.02-1.4)$ & 0.097 \\
H. influenzae positive & $8.4(1.9-37.4)$ & 0.005 \\
Duration of symptoms & $1.0(0.99-1.004)$ & 0.21 \\
Frequent URTI & $0.4(0.1-1.6)$ & 0.21 \\
Snoring & $0.7(0.2-2.4)$ & 0.57 \\
Allergy & $1.3(0.3-6.4)$ & 0.78 \\
Pneumococcal vaccination & $1.4(0.4-4.8)$ & 0.57 \\
\hline
\end{tabular}

apper respiratory tract infections

Bacterial isolation rates from patients with $\mathrm{AOM}$ have been found to range from 50 to $90 \%$, but to be lower (21 to $70 \%$ ) in patients with $\mathrm{OME}[7,9,10]$. The role of bacteria in aetiology of OME has been controversial. OME is not characterized by symptoms and signs of acute inflammation that would be expected in a typical acute bacterial infection caused by planktonic bacteria. The typical bacteria involved in OME are S. pneumoniae, $M$. catarrhalis and $H$. influenzae, but in most studies bacteria were cultured in less than half of the samples, ranging from 21 to $70 \%[7,11,12]$. In our study, positive bacterial cultures were even less (10\%). Although this may suggest that bacteria are not important in OME, it contradicts studies examining MEF for the presence of bacterial nucleic acids by PCR, which have demonstrated bacterial DNA typically in excess of $80 \%$ of effusions [6, 13]. However, the presence of bacterial nucleic acids does not necessarily equate to the presence of viable bacteria as components of effusion samples have been shown to inhibit nuclease activity, and this has been postulated to cause the persistence of RNA and DNA even if bacteria are no longer viable [14]. However, Stoodley et al. [15] using confocal microscopy found that $92 \%$ of a population of children presenting OME had live bacteria (S. pneumoniae, $H$. influenza, and M. catarrhalis) in their mucosal biopsies. These metabolically active bacteria might be present in at least half of all cases of OME with negative bacterial cultures and are thought to participate in biofilm formation [16]. Moreover, Daniel et al. [17] reported that $45.2 \%$ of MEF samples in OME were culture-positive, but $82.3 \%$ were positive by confocal laser scanning microscopy and bacteria viability stain. Combining the two techniques they demonstrated live bacteria in $91.8 \%$ of samples. Rayner et al. [18] have demonstrated the presence of $H$. influenzae mRNA using reverse transcriptase PCR in $43 \%$ of 93 middle ear effusions from children with OME for 3 months or more, when only $12 \%$ were positive on culture. The authors argue that bacterial mRNAs have a half-life of seconds, so their presence indicates viable and metabolically active bacteria. Biofilm formation may be a causative factor in culture-negative OME $[15,16,18]$ since it is a state of very low metabolic activity, almost a suspended animation and bacteria in this state are resistant to antibiotics, but may still elicit an immune response, which will result in the production of the mucin-rich effusion.

Table 4 The associations of epidemiological factors with Streptococcus pneumoniae and Haemophilus influenzae MEF positive samples in children with OME

\begin{tabular}{|c|c|c|c|c|}
\hline \multirow[t]{2}{*}{ Characteristics } & \multicolumn{2}{|l|}{ S. pneumoniae } & \multicolumn{2}{|l|}{ H. influenzae } \\
\hline & OR $(95 \% \mathrm{Cl})$ & $p$ value & OR $(95 \% \mathrm{Cl})$ & $p$ value \\
\hline Age $(y r)$ & $1.7(0.9-3.0)$ & 0.088 & $0.9(0.5-1.5)$ & 0.60 \\
\hline Male sex & $5.1(0.6-44.9)$ & 0.14 & $0.4(0.1-1.5)$ & 0.19 \\
\hline Good social status & $5.3(1.0-28.6)$ & 0.055 & $0.9(0.2-3.6)$ & 0.91 \\
\hline Rural residence & $1.4(0.3-6.0)$ & 0.66 & $0.8(0.2-3.0)$ & 0.70 \\
\hline Parental smoking & $2.5(0.6-11.1)$ & 0.23 & $3.8(0.9-14.8)$ & 0.06 \\
\hline Breastfeeding & - & - & $0.05(0.005-0.6)$ & 0.014 \\
\hline Cesarean childbirth & $1.8(0.4-7.6)$ & 0.44 & $0.6(0.1-2.2)$ & 0.40 \\
\hline Bilateral OME & $0.16(0.02-1.4)$ & 0.097 & $8.4(1.9-37.4)$ & 0.005 \\
\hline Duration of symptoms & $1.0(0.99-1.0)$ & 0.89 & $1.0(0.99-1.0)$ & 0.46 \\
\hline Frequent URTI & $2.6(0.3-23.2)$ & 0.40 & $0.8(0.2-3.7)$ & 0.77 \\
\hline Snoring & $0.3(0.07-1.3)$ & 0.11 & $0.9(0.2-3.7)$ & 0.91 \\
\hline Allergy & $0.7(0.08-6.9)$ & 0.78 & $0.5(0.05-4.5)$ & 0.52 \\
\hline Pneumococcal vaccination & $1.9(0.4-8.5)$ & 0.38 & $1.8(0.5-6.7)$ & 0.41 \\
\hline
\end{tabular}


Indeed, even though $A$. otitidis has been identified by molecular methods in significant proportions of children with acute otitis media (AOM), it is not often isolated from clinical material since the incubation period required for its detection is longer than those used in routine diagnostic laboratories $[19,20]$. The role of $A$. otitidis in pathogenesis of OM is unclear. However, a small number of studies has reported findings that support the hypothesis of $A$. otitidis being a pathogen. The bacteria activated lymphocytes and induced production of pro-inflammatory cytokines in similar amounts as the major middle ear pathogens [21-23].

Considering that $H$. influenzae, S. pneumoniae and $M$. catarrhalis are the most frequent pathogens detected in acute otitis media and are able to ascend through the Eustachian tube, causing ciliary damage to the airway epithelium and disrupting mucociliary flow, this may result in conditions for persistence in the middle ear compartment $[9,10,24,25]$. In some cases, especially when OME is not clearly related to a mechanical obstruction of the Eustachian tube, the Toynbee effect of negative pressure within the middle ear may help the ascendance of microbes through the tube, leading to colonization of the middle ear, which may be pivotal in OME pathogenesis [26].

The most interesting finding in our study was the significant association between bilateral infection and $H$. influenzae aetiology of OME, as well as tendency of association between unilateral OME and S. pneumoniae aetiology. Various social factors have been implicated in the aetiology of OME, most of which are related to socio-economic class, and all of which are probably mediated by an increased propensity to infection. Studies have shown that children who attend day-care centers have a two- to three-fold increased risk of OME. Also greater exposure to respiratory pathogens, both bacterial and viral, and a seasonal variation with the winter preponderance are the reasons for the increase in the incidence of OME [13]. Breastfeeding exerts a protective effect, perhaps by the effect of maternal antibodies on middle ear pathogens [13]. In our study we have made the first attempt to find factors associated with specific bacterial aetiology of OME. Protective effect of breastfeeding along with association with bilateral infection were observed for $H$. influenzae aetiology. There are studies reporting associations between allergy, URTIs, parental smoking, snoring, low social status and chronic/recurrent otitis media, however to our best knowledge none of them determined risk factors associated with particular bacterial aetiology [27].

\section{Conclusion}

Overall we found OME predominantly a single otopathogen infection caused mainly by $A$. otitidis, which is difficult in identification using standard culture method, ahead to S. pneumoniae and $H$. influenzae. However, one third of MEF samples had multiple bacterial pathogens. Definitively, PCR was the more sensitive method for identification of OME aetiology in MEF samples. We have demonstrated significant association between bilateral infection and H. influenzae aetiology of OME.

\section{Supplementary information}

Supplementary information accompanies this paper at https://doi.org/10 1186/s40463-020-00418-5.

Additional file 1: Table S1. The analysis of differences in sensitivity, specificity and positive and negative predictive values of PCR and culture methods in otopathogens identification.

\section{Acknowledgements}

Not applicable.

\section{Authors' contributions}

IKG, AW, contributed with the design of the experiments, performed the experiments, analyzed and discussed the data, and wrote the paper; AM, GN, contributed with the design of the experiments, discussed the data and wrote the paper; MJ, KK, performed the experiments and analyzed the data. All authors read and approved the final manuscript.

\section{Funding}

The authors have no support or funding to report.

Availability of data and materials

The datasets analyzed during the current study are available from the corresponding author on reasonable request.

Ethics approval and consent to participate

The Ethical Committee of the Medical University of Lublin approved the study protocol (No. KE-0254/75/211). From all children's parents, written informed consent was obtained.

Consent for publication

Not applicable.

\section{Competing interests}

The authors declare that they have no competing interests.

\section{Author details}

${ }^{1}$ Department of Pharmaceutical Microbiology, Medical University of Lublin, 1 W. Chodzki Str, 20-093 Lublin, Poland. ²Department of Pediatric

Otolaryngology, Phoniatrics and Audiology, Medical University of Lublin, 6 Prof. A. Gebali Str, 20-093 Lublin, Poland.

Received: 11 November 2019 Accepted: 22 April 2020

Published online: 29 April 2020

\section{References}

1. Minovi A, Dazert S. Diseases of the middle ear in childhood. GMS Curr Top Otorhinolaryngol Head Neck Surg. 2014;13:Doc11.

2. Butler CC, Williams RG. The etiology, pathophysiology, and management of otitis media with effusion. Curr Infect Dis Rep. 2003;5:205-12.

3. Farajzadah Sheikh A, Saki N, Roointan M, et al. Identification of Alloiococcus otitidis, Streptococcus pneumoniae, Moraxella catarrhalis and Haemophilus influenzae in Children With Otitis Media With Effusion. Jundishapur J Microbiol. 2015:8:17985.

4. Harimaya A, Takada R, Hendolin P, Fujii N, Yikoski J, Himi T. High incidence of Alloiococcus otitidis in children with otitis media, despite treatment with antibiotics. J Clin Microbiol. 2006;44(3):946-9.

5. Hendolin PH, Kärkkäinen U, Himi T, Markkanen A, Ylikoski J. High incidence of Alloiococcus otitis in otitis media with effusion. Pediatr Infect Dis J. 1999;18(10):860-5. 
6. Westrberg BD, Kozak FK, Thomas EE, Blondel-Hill E, Brunstein JD, Patrick DM. Is the healthy middle ear a normally sterile site? Otol Neurotol. 2009;30:174-7.

7. Poetker DM, Lindstrom DR, Edmiston CE, Krepel CJ, Link TR, Kerschner JE. Microbiology of middle ear effusions from 292 patients undergoing tympanostomy tube placement for middle ear disease. Int I Pediatr Otorhinolaryngol. 2005;69:799-804.

8. Gok U, Bulut Y, Keles E, Yalcin S, Doymaz MZ. Bacteriological and PCR analysis of clinical material aspirated from otitis media with effusions. Int J Pediatr Otorhinolaryngol. 2001;60:49-54.

9. Holder R, Kirse D, Evans A, Peters T, Poehling K, Swords W, Reid S. One third of middle ear effusion from children undergoing tympanostomy tube placement had multiple bacterial pathogens. BMC Pediatr. 2012;12(87):1-7.

10. Korona-Glowniak I, Mazur E, Zychowski P, Niedzielska G, Koziol-Montewka M, Malm A. Bacterial aetiology of recalcitrant acute otitis media in 62 children-high risk of pathogen colonisation after treatment. Clin Otolaryngol. 2018:43(2):665-9.

11. Kalcioglu MT, Oncel S, Durmaz R, Otlu B, Miman MC, Ozturan O. Bacterial etiology of otitis media with effusion; focusing on the high positivity of Alloiococcus otitidis. New Microbiol. 2002;25:31-5.

12. Mina HK, Kima SH, Parka MJ, Kimb SS, Kima SH, Yeoa SG. Bacteriology and resistance patterns of otitis media with effusion. Int J Pediatr Otorhinolaryngol. 2019;127:109652.

13. Kubba H, Pearson JP, Birchall JP. The aetiology of otitis media with effusion: a review. Clin Otolaryngol Allied Sci. 2000;25:181-94.

14. Peizhong L, Whatmough K, Birchall KJ, Wilson JA, Pearson JP. Does the bacterial DNA found in middle ear effusions come from viable bacteria? Clin Otolaryngol. 2000;25:570-6.

15. Hall-Stoodley L, Hu FZ, Gieseke A, Nistico L, Nguyen D, Hayes J. Direct detection of bacterial biofilms on the middle-ear mucosa of children with chronic otitis media. J Am Med Assoc. 2006;296:202-11.

16. Van Hoecke H, De Paepe AS, Lambert E. Haemophilus influenza biofilm formation in chronic otitis media with effusion. Eur Arch Otorhinolaryngol. 2016;273:3553-60

17. Daniel M, Imtiaz-Umer S, Fergie N, Birchall JP, Bayston R. Bacterial involvement in otitis media with effusion. Int J Pediatr Otorhinolaryngol. 2012;76:1416-22.

18. Rayner MG, Zhang Y, Gorry MC, et al. Evidence for bacterial activity in culture-negative otitis media with effusion. JAMA. 1998;279(4):296-9.

19. Kaur R, Adlowitz DG, Casey JR, Zeng M, Pichichero ME. Simultaneous assay for four bacterial species including Alloiococcus otitidis using multiplex-PCR in children with culture negative acute otitis media. Pediatr Infect Dis J. 2012;29:741-5.

20. Ashhurst-Smith C, Hall ST, Stuart J, Burns CJ, Liet E, Walker PJ. Alloiococcus otitidis: an emerging pathogen in otitis media. J Inf Secur. 2012;64:233-5.

21. Kita H, Himi T, Fujii N, Ylikoski J. Interleukin-8 secretion of human epithelial and monocytic cell lines induced by middle ear pathogens. Microbiol Immunol. 2000:44:511-7.

22. Tarkkanen J, Himi T, Harimaya A, Carlson P, Ylikoski J, Mattila PS. Stimulation of adenoidal lymphocytes by Alloiococcus otitidis. Ann Otol Rhinol Laryngol. 2000;109:958-64.

23. Harimaya A, Himi T, Fujii N, Tarkkanen J, Carlson P, Ylikoski J, Mattila P. Induction of CD69 expression and Th1 cytokines release from human peripheral blood lymphocytes after in vitro stimulation with Alloiococcus otitidis and three middle ear pathogens. FEMS Immunol Med Microbiol. 2005;43:385-92.

24. Emaneini M, Gharibpour F, Khoramrooz SS, Mirsalehian A, Jabalameli F, Darban-Sarokhalil D, et al. Genetic similarity between adenoid tissue and middle ear fluid isolates of Streptococcus pneumoniae, Haemophilus influenzae and Moraxella catarrhalis from Iranian children with otitis media with effusion. Int J Pediatr Otorhinolaryngol. 2013;77:1841-5.

25. Fliegauf M, Sonnen AFP, Kremer B, Henneke P. Mucociliary clearance defects in a murine in vitro model of pneumococcal airway infection. PLoS One. 2013;8:e59925.

26. Buzatto GP, Tamashiro E, Proenca-Modena JL, Saturno TH, Prates MC, Gagliardi TB, Carenzi LR, Massuda ET, Hyppolito MA, Valera FC, Arruda E, Anselmo-Lima WT. The pathogens profile in children with otitis media with effusion and adenoid hypertrophy. PLoS One. 2017;12(2):1-12.

27. Zhang Y, Xu M, Zhang J, Zeng L, Wang Y, Zheng QY. Risk factors for chronic and recurrent otitis media - a meta-analysis. PLoS One. 2014;9:86397.

\section{Publisher's Note}

Springer Nature remains neutral with regard to jurisdictional claims in published maps and institutional affiliations.

\section{Ready to submit your research? Choose BMC and benefit from:}

- fast, convenient online submission

- thorough peer review by experienced researchers in your field

- rapid publication on acceptance

- support for research data, including large and complex data types

- gold Open Access which fosters wider collaboration and increased citations

- maximum visibility for your research: over $100 \mathrm{M}$ website views per year

At BMC, research is always in progress.

Learn more biomedcentral.com/submissions 